\title{
A previously unidentified Chorioptes species infesting outer ear canals of moose (Alces alces): characterization of the mite and the pathology of infestation
}

\author{
Gete Hestvik*1, Monika Zahler-Rinder2,3, Dolores Gavier-Widén", \\ Ronny Lindberg1, Roland Mattsson ${ }^{4}$, David Morrison ${ }^{5}$ and Set Bornstein ${ }^{5}$
}

\begin{abstract}
Address: ${ }^{1}$ Department of Biomedical Sciences and Veterinary Public Health, Swedish University of Agricultural Sciences, Box 7028,75007 Uppsala, Sweden, ${ }^{2}$ Bavarian Health and Food Safety Authority, Veterinärstrasse 2, D-85764 Oberschleissheim, Germany, ${ }^{3}$ Institute for Comparative Tropical Medicine and Parasitology, Ludwig Maximilian University, Leopoldstrasse 5, D-80802 Munich, Germany, ${ }^{4}$ Department of Wildlife, Fish and Environment, National Veterinary Institute (SVA), Box 7073, 75007 Uppsala, Sweden and ${ }^{5}$ Department of Parasitology, National Veterinary Institute (SVA), Box 7073, 75007 Uppsala, Sweden
\end{abstract}

Email: Gete Hestvik* - gete.hestvik@bvf.slu.se; Monika Zahler-Rinder - monika.rinder@lgl.bayern.de; Dolores Gavier-Widén - dolores.gavierwiden@sva.se; Ronny Lindberg - ronny.lindberg@bvf.slu.se; Roland Mattsson - roland.mattsson@sva.se;

David Morrison - david.morrison@bvf.slu.se; Set Bornstein - set.bornstein@telia.com

* Corresponding author

Published: 10 September 2007

Acta Veterinaria Scandinavica 2007, 49:2I doi:10.1I86/I75I-0147-49-2I

This article is available from: http://www.actavetscand.com/content/49/1/2I

(c) 2007 Hestvik et al; licensee BioMed Central Ltd.

This is an Open Access article distributed under the terms of the Creative Commons Attribution License (http://creativecommons.org/licenses/by/2.0), which permits unrestricted use, distribution, and reproduction in any medium, provided the original work is properly cited.
Received: 7 May 2007

Accepted: 10 September 2007

\begin{abstract}
Background: During the past decade, Chorioptes mites occupying the outer ear canals have been a common finding at routine necropsies of moose (Alces alces) in Sweden, but neither the taxonomy of the mites nor lesions from the infestation have been investigated. In this study, the mites are characterized by morphological and molecular techniques, and the histopathology of the skin of the outer ear canal is described.

Methods: External auditory meatuses from 53 necropsied moose were examined for the presence of Chorioptes, and samples from outer ear canals were taken for histopathological and microbiological examination. A proportion of the mites from each moose was identified to species. The DNA was extracted from mites from three moose, and their ITS-2 sequences were determined; these sequences were compared phylogenetically to sequences from other Chorioptes taxa.

Results: Chorioptes mites were found in $43(81 \%)$ of the 53 moose. The mites had morphological and genetic characteristics distinct from those of $C$. texanus and $C$. bovis, the two species generally accepted within the genus. Morphology also did not argue for a diagnosis as $C$. crewei, $C$. mydaus or $C$. panda. On histopathology, lesions were characterized by a hyperplastic perivascular to interstitial dermatitis with epidermal hyperkeratosis and crust formation. Dermal inflammatory infiltrates were composed of mixed T- and B-lymphocytes, plasma cells and macrophages, whereas eosinophils were notably uncommon. Staphylococcus aureus was grown from the infested epidermis of five of 14 examined moose.

Conclusion: Chorioptes mite infestation was frequently detected in the outer ear canals of moose in Sweden. The mites were evidently pathogenic, being associated with inflammatory lesions of the external auditory meatus. Our studies indicate infestations with a previously undescribed Chorioptes species.
\end{abstract}




\section{Background}

Ectoparasites of the genus Chorioptes (Acari: Psoroptidae) are distributed worldwide, infesting domestic as well as wild herbivores [1,2]. These non-burrowing mites are commonly found on cattle, sheep, goats, horses and the New World camelids, where they are a common cause of mange and have considerable veterinary importance. The affected skin areas vary with host and degree of infestation, but the extremities or tail regions are commonly involved. The entire life cycle, from egg-laying through larval and nymphal stages to mature mites, takes place on the same host, and spans approximately three weeks [3].

At present, the taxonomy of Chorioptes is unclear. Two species, Chorioptes bovis (Hering, 1845) and Chorioptes texanus Hirst 1924 are generally accepted $[1,4]$, based on morphology and genetic differentiation, while the existence of three further species, Chorioptes crewei Lavoipierre 1958, Chorioptes mydaus Fain 1975 and Chorioptes panda Fain and Leclerc 1975, is still questionable $[2,5]$. Both C. bovis and $C$. texanus are ubiquitous mites with a low degree of host specificity. These mites are mostly found to infest the skin surface of the body, and are rarely found in the ears of the hosts $[4,6]$. One exception is reindeer (Rangifer tarandus), in which C. texanus has been considered to be a primarily auricular mite [7]. C. texanus has also been isolated from cattle (Bos taurus), goats (Capra hircus), roe deer (Capreolus capreolus), sika deer (Cervus nippon) and moose (Alces alces) [1,5,8-13]. Reported hosts of C. bovis include wild and domestic Bovidae, Cervidae, Equidae and Camelidae [4].

Moose are widely distributed and inhabit almost all rural parts of Sweden. The population amounts to approximately 300,000 during summertime, but is reduced to about 200,000 by hunting in fall [14]. Compilation of diagnoses at routine necropsies at the National Veterinary Institute (SVA) 1986-91 showed various diseases in the Swedish moose population. Among the most frequent diagnoses were traumatic injury, microbial infectious disease, elaphostrongylosis and tumours [15].

Otoacariasis caused by Chorioptes was confirmed to occur frequently in Swedish moose found dead or shot in the field and examined at SVA during the last decade [16]. Preliminary studies on the mite indicated a hitherto undescribed taxon of Chorioptes. To the best of our knowledge the lesions associated with Chorioptes infestation in moose have not been reported. In the present study, the morphological and molecular characteristics of the mite are reported, and the pathology of the infestation in the outer ear canal of moose is described.

\section{Methods \\ Source of material}

Moose found dead or shot in the field were submitted to SVA during the period 1997 and 2000-2006, and examined as part of a health monitoring programme. External auditory meatuses from 53 necropsied moose, sampled at convenience, were examined for the presence of Chorioptes spp. The degree of post-mortem change in the carcases ranged from mild to marked. Forty-three of the moose originated from seven counties in central Sweden (Stockholm, Uppsala, Sörmland, Örebro, Västmanland, Dalarna and Gävleborg), and 10 from more southerly regions (the counties of Östergötland, Kalmar, Skåne, Halland and Älvsborg). The nutritional state was judged to be normal, subnormal or cachectic (with serous atrophy of fat). The age of the moose was estimated by cementum ageing analysis [17]; and the sex was recorded in 50 animals.

Both outer ear canals of each moose were investigated. The ears with their attached earflaps were cut away as close to the scalp as possible. The ear canals were dissected from attached tissues, and a segment $2-4 \mathrm{~cm}$ long of the inner part of the canals was removed. All moose were subjected to parasitological examination, while 28 and 14 were subjected to histopathological and microbiological examination, respectively. No examination for mites was performed on the skin and fur of other body sites.

\section{Parasitological examination}

The ear-canal samples were cut open, exposed to $25-27^{\circ} \mathrm{C}$ for $30 \mathrm{~min}$, after which the inner surface of the canals was examined under a stereomicroscope. If no mites were observed, skin scrapings were obtained and treated with $10 \% \mathrm{KOH}$ for 5 hours. After centrifugation, the supernatant was discarded, and a few drops of glycerin were added to the sediment, which was then searched for mites. A proportion of the mites from each moose was identified to species. In 32 moose the level of infestation with mites was subjectively scored: low $(\mathrm{n}=\leq 10)$, mild $(\mathrm{n}=>10-$ $\leq 50)$, moderate $(n=>50-\leq 500)$, or high $(n=>500)$. When degrees of infestation differed between the ears, the scoring was based on the most heavily infested ear, and moose with one ear negative and the other positive were scored according to the positive ear.

\section{Morphological investigations of mites}

Diagnosis of the mites to genus was made according to Fain [18], while Chorioptes species differentiation was based on a key given by Fain and Leclerc [19]. Opisthosomal seta 1, 2 and 3 located at the opisthosomal lobes, and seta 4 originating from the caudal body margin between the opisthosomal lobe and leg 4, as well as seta 5 located at tarsus III, were measured in up to 20 male mites isolated from three moose (seta numbering according to Sweatman [7]). For comparison, these setae were also 


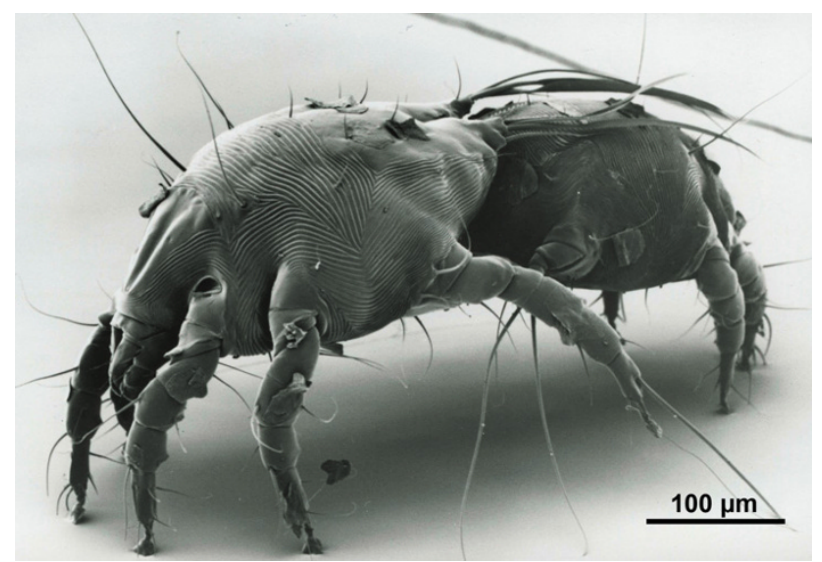

Figure I

Scanning electron micrograph of two Chorioptes mites (a couple). The mites were obtained from the outer ear canal of one of the moose, and their morphology was described in detail in this study.

measured in up to 40 male C. texanus mites collected from cattle in Germany. Statistical comparisons were done using the Student's $t$-test.

\section{DNA extraction, polymerase chain reaction and sequencing}

Up to $25 \mathrm{mg}$ of each skin scraping from three moose (M289, M290 and M291) was frozen in liquid nitrogen and grounded to a fine powder. DNA was then extracted using the QIAamp DNA mini kit (Qiagen, Hilden, Germany) according to the instructions of the manufacturer, and eluted in $50 \mu$ l elution buffer. Primers RIB-4 (CCA TCG ATG TGA A(C,T)T GCA GGA CA) and RIB-3 (CGG GAT CCT TC $(A, G)$ CTC GCC G(C,T)T ACT) were originally designed for the amplification of the second internal transcribed spacer (ITS-2) of the rDNA from Dermacentor ticks [20]. Polymerase chain reaction (PCR) amplifications, as well as cloning and sequencing, were done with $5 \mu \mathrm{l}$ of the DNA solution as described elsewhere [5].

\section{Molecular sequence analysis}

Consensus ITS-2 sequences, here called genotypes, were constructed manually by comparing alignments obtained using the Clustal W (version 1.83) algorithm [21]. Mutations at a given position occurring in only a single clone were classified as polymerase errors, or (indistinguishable from them) as rare genotypes, and were not included in the genotype sequence. Mutation rates were calculated by counting substitutions, deletions and insertions as one mutation each, and dividing the sum by the average length of the sequences. Identities were determined as differences between $100 \%$ and the respective mutation rate. To estimate genetic variation between different individu- als within a representative skin scraping, and the frequency of polymerase errors and rare polymorphisms, ten clones generated in ten PCR reactions from DNA obtained from moose M290 were sequenced. In the sequences obtained from the other skin scrapings, mutations at sites that had not previously been demonstrated to be polymorphic were verified by at least one other clone originating from an independent PCR amplification.

For comparison, representative ITS-2 sequences obtained from C. texanus and C. bovis using the same PCR protocol and cloning strategies [5] were included in the analysis [EMBL:EF191362， EMBL:EF191363， EMBL:EF191364, EMBL:EF191369, EMBL:EF191372, EMBL:EF191375], as well as other Chorioptes ITS-2 database sequences

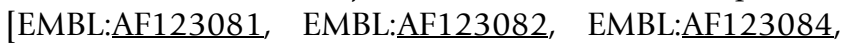
EMBL:EF053119， EMBL:EF053120， EMBL:EF053122， EMBL:EF053123]. Sequences from two other members of the Psoroptidae, Otodectes cynotis [EMBL:AF367699] and Psoroptes [EMBL:EF429269], were used as the outgroup.

The initial multiple sequence alignment was produced using Clustal W, and then manually modified so that it was consistent with the mite ITS-2 secondary-structure model [22]. The fit of the sequences to this model was assessed using the MFold (version 3.2) program [23]. The final alignment had 309 positions for the ITS-2 region of 287 bp (bases 45-331 of [EMBL:EF433564]).

Phylogenetic trees were produced via both maximum parsimony and maximum likelihood algorithms, using the PAUP* (version 4.0b10) package [24]. Maximum-parsimony heuristic searches used 100 random-addition sequences of TBR branch swapping, as well as 20 replications of the parsimony ratchet [25] based on 200 iterations of TBR branch swapping. Maximum-likelihood heuristic searches used the ratchet (Nixon) [26] strategy based on 100 iterations of TBR branch swapping. The GTR+G substitution model was used, determined after preliminary testing with the ModelTest program [27], and the parameter values (fixed during the searches) were estimated using successive approximations [28].

Support for the phylogenies was measured by bootstrapping. For the maximum-parsimony analyses this was based on 2,000 pseudoreplicates, each with 100 randomaddition sequences of TBR branch swapping, while for maximum-likelihood analyses it was based on 200 pseudoreplicates, each with 10 random-addition sequences of TBR branch swapping.

\section{Histopathological examination}

Pieces of the sampled inner ear canals were fixed in $10 \%$ neutral buffered formaldehyde, embedded in paraffin, and routinely processed for histopathology. Sections cut 4 
$\mu \mathrm{m}$ thick were routinely stained with haematoxylin and eosin (HE), and selected sections were stained with periodic acid Schiff (PAS) for aid in identification of parasites, Grocott for fungi, Gram's stain for bacteria, toluidine blue for mast cells, and Lendrum's method for eosinophils [29]. For further characterization of inflammatory cells, skin specimens from five moose were investigated for lymphocyte subsets, employing monoclonal mouse antihuman antibodies CD3 F7.2.38 (Dakocytomation, Glostrup, Denmark) and CD79 $\alpha$ cy (Dakocytomation, Glostrup, Denmark) for T-cells and B-cells respectively, in the Dako EnVision $+{ }^{\circledR}$ system.

\section{Microbiological examination}

Smears from pieces of the sampled inner ear canals were plated onto Blood Agar Base (Difco) with 5\% horse blood and Blue-agar Base with 1\% glucose for bacteriological culture. The plates were incubated at $37^{\circ} \mathrm{C}$, and inspected for growth after 24 and 48 hours. For mycological examination, the smears were plated onto $2 \%$ Sabouraud glucose agar (Difco) with chloramphenicol. The plates were incubated in an aerobic environment at $27^{\circ} \mathrm{C}$, and inspected for a period of 10 days. Isolated strains were recultured, and identified by morphological and physiological characteristics according to standard methods.

\section{Results}

Infested moose were found in all parts of the study area, covering the mid and south regions of Sweden. Of the 53 moose examined parasitologically, 43 (81\%) were infested with Chorioptes sp. Five of those only had one ear infested. The degree of infestation was scored in 32 moose, in 7 it was low, in 8 mild, in 11 moderate and in 6 moose it was high. Twenty-eight moose had similar degrees of infestation in both ears, while in two moose the degree of infestation between ears varied, and two had only one ear infested.

Of the infested moose, 33 were females and eight were males, whereas the sex was not recorded in two animals. Nine moose showed a subnormal nutritional state, and 21 were cachectic. The 10 non-infested moose included six females, three males and one with the sex not recorded. Four of them had a subnormal nutritional state, and two were cachectic. The age distribution of both infested and non-infested moose ranged from calves to 23 years. As judged from post-mortem records, the panorama of necropsy diagnoses did not differ between infested and non-infested animals, and was similar to that found in the material of Swedish moose necropsied at SVA 1986-1991 [15].

\section{Morphology of mites}

The mites were identified as Chorioptes, based on males with short pedicles and caruncles (suckers) at legs III and
IV, a single long seta at tarsus of legs III, as well as with legs III about twice as long as legs IV (Figure 1 and 2A). The opisthosomal lobes were as long as wide, and bore five setae. Three long and strong setae (setae 14,15 and $d 5$ according to Fain [18]; seta 15 corresponds to seta 2 in figure $2 \mathrm{~B}$ and table 1 ) arose, very close to each other, from the apical margin of the lobe. Two of these setae, 14 and $d 5$, were flattened and blade-like at their apical thirds, while seta 15 (seta 2) did not increase in width apically. A fourth seta (seta 1 according to Sweatman [7]; seta ae according to Fain [18]) was shorter than the three setae mentioned above, and arose latero-apically at a small accessory lobe forming a small angle with relation to the main lobe. This seta was separated by a distinct gap from the group of the three other setae (Figure 2). The fifth opisthosomal seta was very short and fine. It was found at the medial side of the lobe and arose dorsally.

Within Chorioptes, the mites detected in moose in Sweden were found to have more or less quadrangular opisthosomal lobes, and outer opisthosomal setae ae (seta 1) distinctly shorter than setae 14, 15 (seta 2) and d5, which arose as a group close to each other (Figure 2). They were therefore clearly different from both $\mathrm{C}$. bovis and $\mathrm{C}$. crewei, and more similar to descriptions of mites C. texanus, C. mydaus and C. panda.

In comparison to male C. texanus isolated from cattle in Germany, the male Chorioptes from Swedish moose possessed longer opisthosomal setae 1 ( $\operatorname{seta} a e), 2$ (seta 15) and 3 (seta 24 ), while setae 4 and 5 did not differ signifi-

Table I: Lengths $(\mu \mathrm{m})$ of the five setae in male Chorioptes mites.

\begin{tabular}{|c|c|c|}
\hline No. of seta (location) & $\begin{array}{l}\text { Chorioptes sp. } \\
\text { from moose }\end{array}$ & $\begin{array}{l}\text { C. texanus from } \\
\text { cattle }\end{array}$ \\
\hline & $\begin{array}{l}\text { mean } \pm S D \\
\text { range } \\
n\end{array}$ & $\begin{array}{l}\text { mean } \pm S D \\
\text { range } \\
n\end{array}$ \\
\hline I (at the opisthosomal lobe) & $\begin{array}{l}85.3 \pm 9.3^{*} \\
71-106 \\
20\end{array}$ & $\begin{array}{l}54.2 \pm 7.3^{*} \\
37-69 \\
40\end{array}$ \\
\hline 2 (at the opisthosomal lobe) & $\begin{array}{l}234 \pm 14^{*} \\
\mid 98-251 \\
19\end{array}$ & $\begin{array}{l}164 \pm 8^{*} \\
145-185 \\
40\end{array}$ \\
\hline 3 (at the opisthosomal lobe) & $\begin{array}{l}28.8 \pm 3.7^{*} \\
24-40 \\
13\end{array}$ & $\begin{array}{l}24.3 \pm 5.4^{*} \\
13-32 \\
31\end{array}$ \\
\hline 4 (at the caudal body margin) & $\begin{array}{l}26.3 \pm 2.9 \\
19-32 \\
19\end{array}$ & $\begin{array}{l}24.9 \pm 3.9 \\
16-32 \\
38\end{array}$ \\
\hline 5 (at tarsus III) & $\begin{array}{l}21.1 \pm 5.4 \\
13-32 \\
17\end{array}$ & $\begin{array}{l}18.3 \pm 7.2 \\
8-40 \\
35\end{array}$ \\
\hline
\end{tabular}

\footnotetext{
$\mathrm{n}=$ number of measurements

$\mathrm{SD}=$ standard deviation

* differences were significant at $p<0.01$, based on $t$-test.
} 


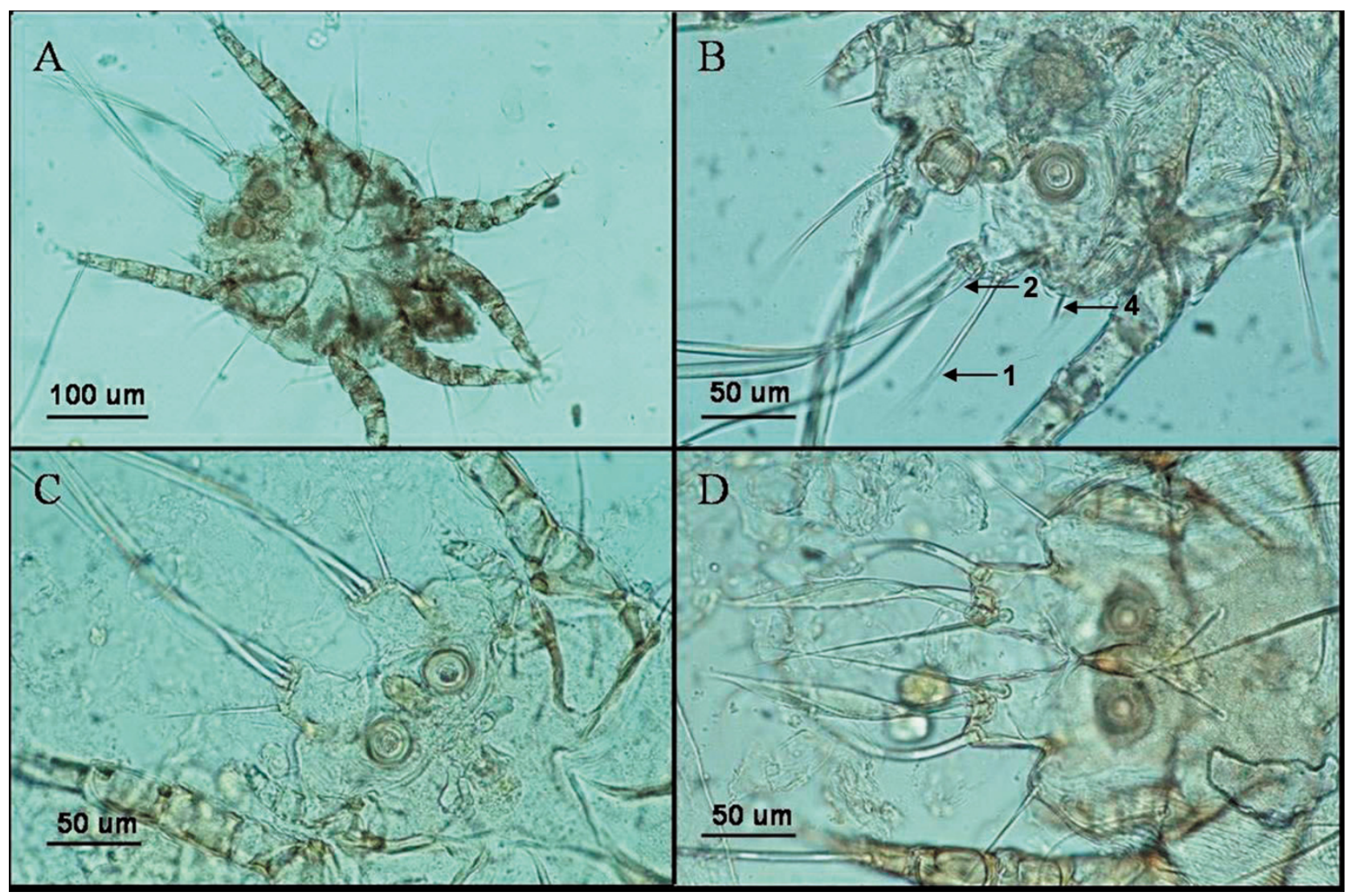

Figure 2

Light micrographs of individual male Chorioptes mites, showing the caudal end with opisthosomal lobes. A: Chorioptes sp. sampled from Swedish moose, overview. B: Chorioptes sp. sampled from moose, details. Measured setae I, 2 and 4 are indicated by arrows. Seta 3 and seta 5 cannot be seen. C:C. texanus collected from cattle in Gemany. D: $C$. bovis sampled from horse in Germany.

cantly in length (table 1). The differences were most evident in seta 1 being $85 \mu \mathrm{m}$ long on average in the mites from moose, compared to an average length of $54 \mu \mathrm{m}$ in the C. texanus mites. This seta was also thicker in the mites from moose than in C. texanus (Figure 2). Additionally, the accessory opisthosomal lobe bearing seta 1 seemed to be smaller and proximally positioned in the mites from the moose (Figure 2).

\section{Molecular investigations}

DNA sequences between primers RIB-3 and RIB-4, varying in length between 388 and $390 \mathrm{bp}$, were determined from ten clones originating from independent PCR amplifications using DNA extracted from skin scraping materials of moose M290. Taq polymerase errors and rare polymorphisms (which are indistinguishable), determined as individual mutations not found in any other sequenced clone, were detected at seven positions (six substitutions and one 1-base deletion) in seven of the ten clones, corresponding to a rate of $0.2 \%$.

After excluding Taq polymerase errors and rare polymorphisms from further analysis, nine polymorphic positions, including seven substitutions as well as one 1-base and one 2-base insertion/deletion, were detected, resulting in eight different sequence types here called genotypes. Seven genotypes were found in the ten sequences of mites from moose M290, while two and three genotypes were obtained from mites collected from moose M289 and M291, respectively. Genotype 1 was the genotype detected most frequently, being found five times and in mites from all the three host animals. Genotype 2 included three sequences from moose M290 and M291, while two sequences were affiliated to genotype 3 from moose M289 and M290. All of the other genotypes were detected only once. The identities between the different genotypes varied from $97.5-99.7 \%$. The sequences are 


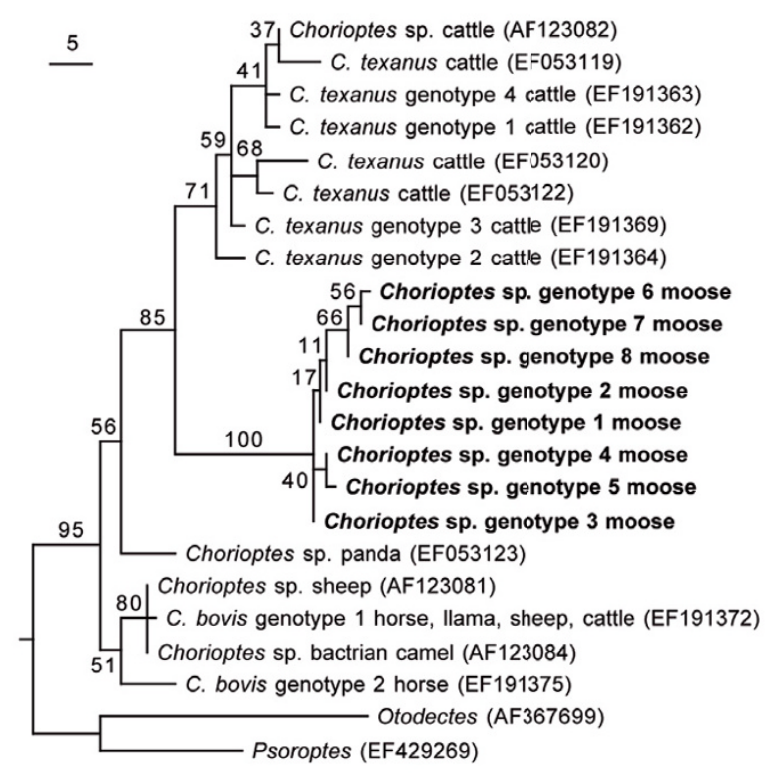

Figure 3

Maximum-likelihood phylogenetic tree of Chorioptes spp. based on complete ITS-2 DNA sequences. The corresponding sequences of Psoroptes and Otodectes were used as the outgroup (midpoint rooted). Bootstrap values are given as percentages for each node. The scale indicates the expected number of nucleotide substitutions. Database accession numbers of the sequences are given in brackets. The sequences from the Chorioptes mites from Swedish moose are in boldface.

available under the database accession numbers [GenBank:EF433564-EF433575].

The phylogenetic analyses produced a single maximumlikelihood tree (Figure 3) and 404 maximum-parsimony trees. The majority-rule consensus of the maximum-parsimony trees differed from the maximum-likelihood tree only in being less resolved; and the bootstrap support for the relevant branches was also approximately the same. The sequences of the Chorioptes mites from the moose formed a distinct monophyletic group in these trees, with a sister-group relationship to $C$. texanus. The support for the C. bovis group was poor, due to ambiguous support for the inclusion or exclusion of both genotype 2 and the Chorioptes taxon sampled from panda.

\section{Histopathology}

In ears negative for Chorioptes, the epidermis consisted of 2-4 layers of epithelial cells. Over a single straight layer of basal cells were one or two layers of spinosum cells, mostly followed by one layer of granular cells. The thickness of the stratum corneum was somewhat variable, and occasionally exceeded the thickness of the cellular layers (Figure 4). In the superficial dermis were scattered T- and B-lymphocytes, plasma cells and occasional mast cells.

In ears with mites, the epidermis was in general moderately, and sometimes severely, hyperplastic. Mixed orthokeratotic and parakeratotic hyperkeratosis was a frequent feature, and in nine cases serocellular exudation with degenerated neutrophils and crust formation was seen (Figures 5A and 5B). Mild to moderate exocytosis of neutrophils into the epidermis occurred in seven cases. In 13 moose, intact mites or mite fragments were lying free on the surface among keratin fragments, or embedded in crusts (Figure 5C). Some cases showed mild to moderate spongiosis, and occasional vacuolated keratinocytes were found in the spinous and granular strata. Six moose had ulcerations in one or both ears, generally shallow, but occasionally deep. In four moose, ulcerations were acute, with neutrophil-rich serocellular exudates, and sometimes haemorrhages, whereas two moose showed chronic ulcers with fibrosis. In the dermis, mostly mild to moderate, but occasionally severe, perivascular to interstitial inflammatory infiltrates occurred consistently (Figures 5D and 5E). Superficial to mid-dermal infiltrates were as a rule dominated by T-cells and plasma cells, with an admixture of macrophages (not further characterized) and, in six moose, sparse eosinophils. Compared to noninfested ears, any increase of mast cells was not evident. Where inflammation extended to the deep dermis, the infiltrate was mainly perivascular and plasmacellular. Mild to moderate vascular congestion was common. Both ceruminal and sebaceous glands often showed mild to moderate hypertrophy, with the addition of moderate hyperplasia in ceruminal glands. All sections stained for fungi were negative. Small amounts of bacteria (grampositive cocci) were found superficially on the skin surface or in crusts in a few ears.

\section{Microbiology}

Among the 14 moose subjected to bacterial cultivation, Staphylococcus aureus was grown from five and Staphylococcus spp. from one moose, all mite-infested. Of the eight moose negative for bacterial culture, four were miteinfested. Yeasts, not further characterized, were cultured from two moose, both non-infested.

\section{Discussion}

This study showed that Chorioptes sp. was frequently detected in the outer ear canals of moose (Alces alces) in Sweden. In wildlife, localization of Chorioptes mites in the outer ear canals has also been described in reindeer, Rangifer tarandus [7], red-flanked duiker, Cephalophus rufilatus [30] and giant panda, Ailuropoda melanoleuca [19]. In this study the skin of other parts of the body of the moose was not examined for mites and therefore it is not known if 


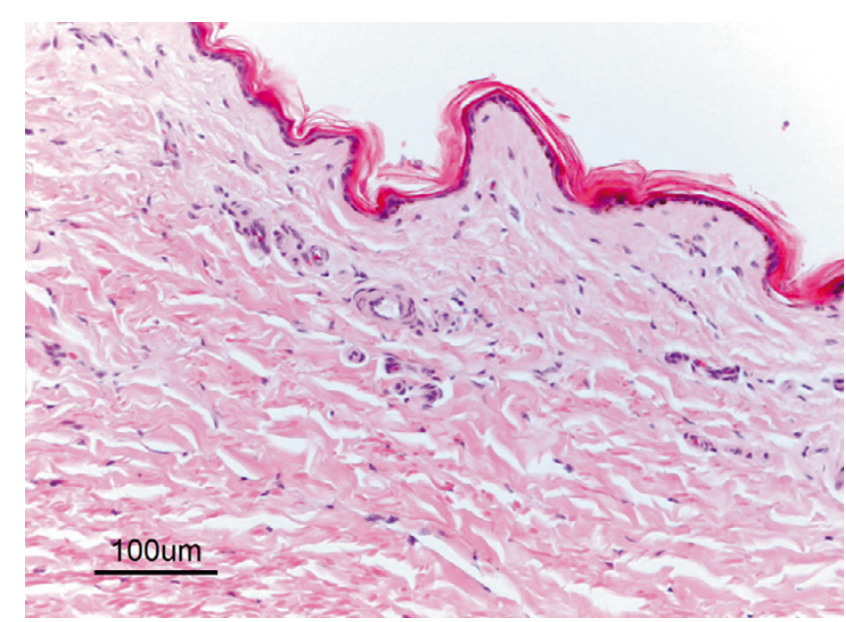

Figure 4

Histology of normal skin from the outer ear canal in a moose not infested with Chorioptes. HE. The epidermis is thin and the thickness of the stratum corneum exceeds that of cellular layers. Scattered lymphocytes in the superficial dermis.

the Chorioptes infestation was restricted to the ear canals. Moreover, Chorioptes sp. have been found on alopecic areas of the skin in moose necropsied at SVA, and in one case Chorioptes were also demonstrated in the outer ear canals (pers. comm. C. Bröjer). However, these mites have not yet been closely compared to the Chorioptes sp. isolated from the external ear canals of the moose of this study.

The evidence presented here indicates that the Chorioptes sp. found is a previously undescribed species, which will be described in detail in a later publication. The Chorioptes sp. was closest to C. texanus, based on both morphology and genetics including cloning and sequencing of multiple independent PCR products from skin scrapings, in order to recognize different sequence types that might originate from different individual mites present in the skin, or from different copies of the rDNA which represents a multi-copy gene [5].

Morphological differentiation between C. texanus and C. bovis is mainly based on the setae at the opisthosomal lobes in male mites (Figure 2). The outer opisthosomal seta, called seta $1[4]$ or seta ae [18], is much longer in $C$. bovis than in C. texanus, with a length $>100 \mu \mathrm{m}$ and $<100$ $\mu \mathrm{m}$, respectively $[5,7,31]$. The mites from moose possessed shorter setae than those of C. bovis. Furthermore, they had longer opisthosomal setae 1, 2 and 3 compared to $C$. texanus mites from cattle. Whether the ear mites of reindeer, affiliated to C. texanus [7], might actually belong to the same species as the ear mites from moose of this study, can not be decided, since mites were not available for direct morphological and molecular comparison.

When the genotype sequences from the Chorioptes mites from moose were compared with sequences from $C$. texanus and C. bovis obtained using the same protocols [5], pairwise identities from the different Chorioptes moose genotypes were $89-91 \%$ (C. texanus) and $86-89 \%$ (C. bovis). These inter-species identities were thus of the same order as the identity of $89-93 \%$ found between C. texanus and C. bovis [5], for which separate species status is generally accepted. Furthermore, phylogenetic analyses (which were robust to the form of analysis used) indicated that the moose mites formed a monophyletic group, with a sister-group relationship to C. texanus. This separation is interpreted here as an indication of taxonomic separation and not as a reflection of the geographic origin of the mites, because the corresponding sequences of $C$. texanus and $C$. bovis grouped according to taxonomic entities and not the geographical origin of the mites, and the mites from Swedish moose did not group together with Chorioptes mites of their nearest geographical origin. Thus, there is no molecular support, either from genetic similarity or sister-group relationships, for placing the Chorioptes mites from Swedish moose in either C. texanus or C. bovis.

In the past, moose have been described as being parasitized by $C$. texanus in Poland $[11,12]$, although neither pictures nor descriptions of the mites were given. These mites might be different from those that we found in moose in Sweden, because the mites in Poland were not found in the auricles of the animals but only at several other body sites [12]. We did not investigate non-auricular body sites in our study, leaving open the question as to whether other species of Chorioptes, such as C. texanus, are also found in moose in Sweden or if the Chorioptes sp. identified in this study affects other parts of the skin besides the ear canal.

The species status of the other three Chorioptes species seems doubtful [2]. C. crewei was based on morphological features of only four females and two males taken from the ears of a red-flanked duiker (Cephalophus rufilatus) in Cameroon [30,32], and detection of this species has never been documented afterwards. Mites of $C$. mydaus were isolated only once from a stink badger (Mydaus lucifer) in Borneo [18], and those of $C$. panda were found in the ears of giant pandas (Ailuropoda melangolenca) in zoos in France [19] and China [33]. Affiliation of the mites from Swedish moose with C. mydaus or C. panda was difficult to determine, since mites of these questionable species were not available for direct comparison. Morphological comparison was thus limited to published descriptions and drawings $[18,19,33]$, which allowed only limited conclusions. The mites from the moose differed from C. mydaus 


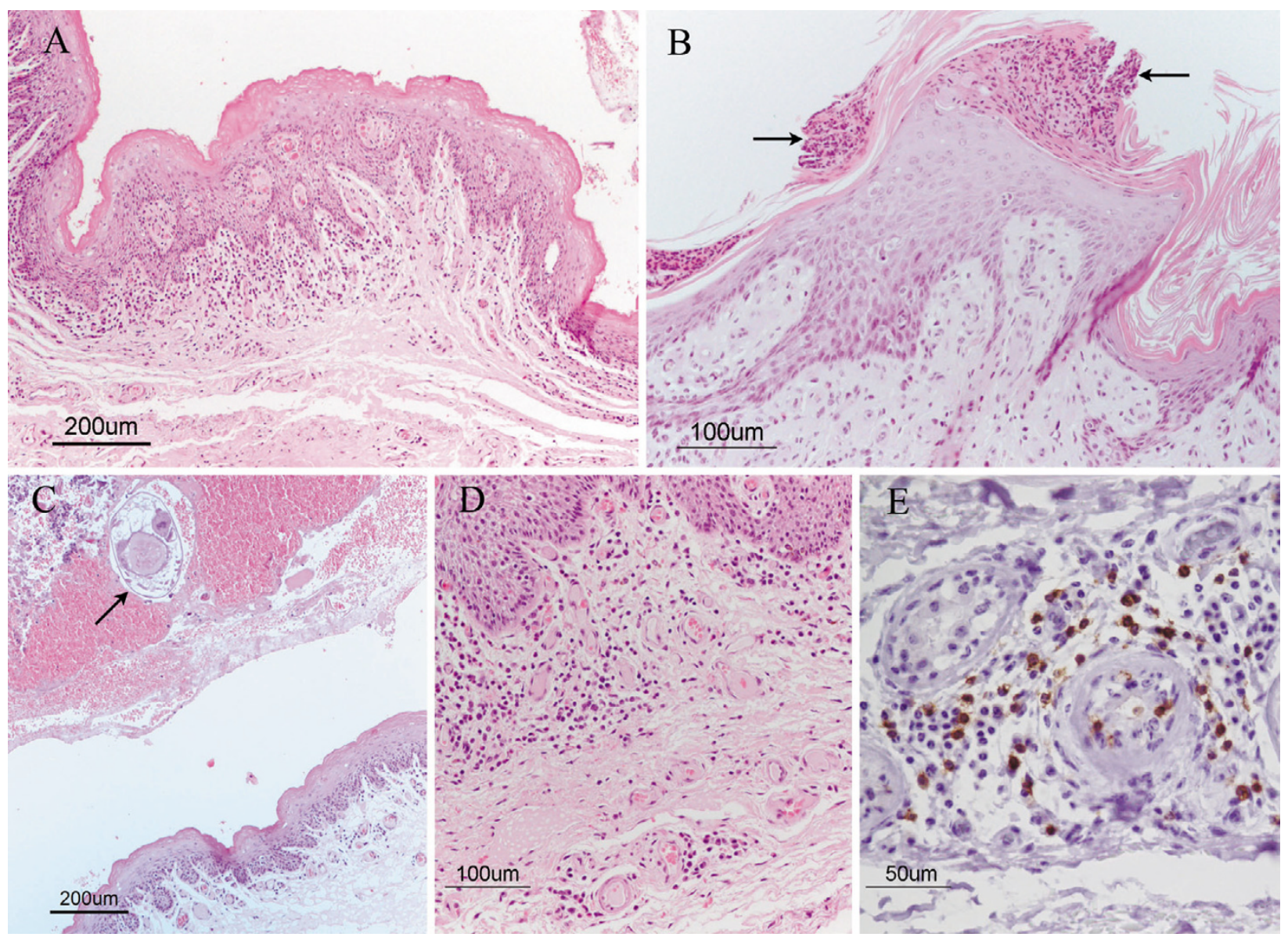

\section{Figure 5}

Histopathology of the skin from the outer ear canal in a Chorioptes-infested moose. A: Marked epidermal hyperplasia with prominent rete ridges (acanthosis) and orthokeratotic hyperkeratosis. HE. B: Acanthotic epidermis with multifocal crust formation (arrows) and mixed inflammation in dermis. HE. C: Haemorrhagic crust with embedded cross-sectioned mite (arrow), on epidermis. HE. D: Dermal inflammation, showing lymphocytes, plasma cells and some macrophages with a perivascular to interstitial distribution. HE. E: Immunohistochemistry for CD3 F7.2.38 (T-lymphocytes stained brown), showing perivascular infiltrate of T-lymphocytes and plasma cells in deeper parts of the dermis. En-Vision ${ }^{+\circledR}$ with haematoxylin.

by a shorter seta $a e$, which was $85 \mu \mathrm{m}$ on average compared to $100 \mu \mathrm{m}$ in C. mydaus [18]. Additionally, setae 14 and $d 5$ were of a distinct flattened, blade-like shape in the mites from moose (Figure 2), while they were described and drawn to be small or only slightly widened in $C$. mydaus [18]. The moose mites were regarded as morphologically closer to $C$. panda based on drawings [19]. The most evident differences were that in C. panda seta ae was less separated by setae 14,15 and $d 5$, and all of these 4 setae arose at an oblique line from the opisthosomal lobe [19], while there was a distinct gap between seta ae and the other three seta mentioned in the mites from the moose, and the seta $a e$ arose proximal to a line of the points of origin of setae 14,15 and $d 5$ (Figure 2). These differences, however, could not be detected in the drawings of $C$. panda by other authors [33].

No evidence was found to affiliate the Chorioptes sp. with any of these taxa. The sequence from mites sampled from panda in China [EMBL:EF053123], although not affiliated to a particular mite species, appears to exclude $C$. panda as a possible identification of the moose mite.

A high percentage of the moose ( $81 \%)$ was shown to be Chorioptes-infested. Additionally the true prevalence of infestation might actually have been higher since in many cases the moose had been dead for several days, and the mites may had left the carcase. The direct ocular method 
employed, i.e. raising the temperature of the sampled pieces of ear canals, stimulated the live mites to migrate and thus facilitated their detection and collection. This method is able to detect live mites that are present in relatively high numbers. Detection of mites by skin scrapings, also performed in this study, is more frequently used [34], and demonstrates only a proportion of the mites actually present. Also, it does not distinguish live from dead mites. In addition, non-burrowing mites may occasionally be found in histological sections, however, most of the mites on the skin surface may be lost during the histological processing.

The majority of the moose were in a poor nutritional state, ranging from subnormal to cachectic. Mite-infested animals were more often recorded at necropsy as cachectic than were uninfested moose. However, possible associations between Chorioptes infestation and the nutritional state and other factors, including age, sex, season and concomitant diseases, were not analyzed because the sample was obtained from animals found dead in the field at different times of the year and sent for diagnostic post-mortem examination. This resulted in a great variability in host related factors and possible biases in sampling.

Since the samples were from wild animals, no observations on the duration of the infestations could be performed. The histopathological changes, however, suggested that most cases were subacute or chronic. Studies describing the pathology of chorioptic mange in various species, including ruminants, are few, and only concern mange caused by $C$. bovis. The epidermal changes seen in the moose, characterized by hyperplasia with ortho- and parakeratotic hyperkeratosis, sometimes with serocellular exudates and crusts, were similar to those described in sheep and a Japanese serow (Capricornis crispus) $[35,36]$.

Eosinophils are common in allergic reactions, including those of ectoparasitic origin [37-39]. The inconsistent and sparse dermal tissue eosinophilia in the moose is in contrast to findings in C. bovis-infested cattle and horses, in which eosinophils were numerous $[37,40]$, but are in accordance with observations in sheep with this mite [35].

In dermal allergic hypersensitivity reactions in domestic animals, a superficial perivascular distribution of inflammatory cells is commonly predominant $[37,38]$. Despite the type of hypersensitivity reaction, T-lymphocytes dominate, while B-lymphocytes and plasma cells are present in lesser amounts $[38,39]$. The dermal inflammation in the moose was characterized by perivascular to interstitial infiltrates of T-lymphocytes, plasma cells and B-lymphocytes, suggesting that also in the moose the reactivity may involve a hypersensitivity reaction. In C. bovis- infested sheep, macrophages, lymphocytes and plasma cells were found perivascularly in the superficial dermis, and the reaction was proposed to represent an allergic contact dermatitis [35].

Dermal infiltrates of plasma cells were prominent in the moose. Plasma cells are reported to be common in interstitial dermatitis in large domestic animals, and may be considered to be of low significance [37]. However, in dogs and cats, plasma cells are described as predominant in late stage pyoderma, but are less frequent in allergic hypersensitivity reactions [38]. A bacterial cause of the prominent plasma cell infiltration in the moose should be considered, because staphylococci, mainly Staphylococcus aureus, were cultured from the moose's ear skin in $6 / 10$ infested ears, but in none of the non-infested moose. Nonetheless, in many species $S$. aureus belongs to the normal skin flora [41], and this could also be the case in the skin of the outer ear canals of moose. Irrespective if the ears were cultured positive for staphylococci or not, dermal infiltrates of plasma cells were a feature. Hence, an association between presence of plasma cells and positive culture could not be established. This might indicate another cause than bacterial infection to the plasma cell prominence.

\section{Conclusion}

Chorioptes sp. was frequently detected in the outer ear canals of moose (Alces alces) in Sweden. This mite has morphological and genetic characteristics distinct from those of C. texanus and C. bovis, the two species generally accepted within the genus. Morphology also did not unequivocally argue for a diagnosis as C. crewei, C. mydaus or C. panda, and thus we argue that the mites belong to a proposed new species. The mites were obviously pathogenic to the moose, evoking epidermal and dermal inflammatory lesions, the latter indicating immunological hypersensitivity reactions.

\section{Competing interests}

The author(s) declare that they have no competing interests.

\section{Authors' contributions}

GH carried out the histopathological examinations, and wrote the first draft of the manuscript. MZR carried out the morphological and molecular studies, and wrote the first draft of the manuscript. DGW conducted the preliminary histopathology, collected samples, blocked the tissues and contributed to the manuscript. RL contributed to histopathological description and to the manuscript. RM carried out the bacteriological and mycological investigations. DM contributed to the data analyses, and revised and edited the manuscript. SB initiated and coordinated the study, collected the samples, carried out the 
parasitological investigations, and contributed to the manuscript. All authors read and approved the final manuscript.

\section{Acknowledgements}

Thanks to: Karin Bernodt, Caroline Bröjer, Jonas Malmsten, Henrik Uhlhorn and Erik Ågren for the collection of samples; Ewa Backman for the compilation of data; personnel at the histology lab at SVA for technical help; Ewa Westergren for conducting special stains and immunohistochemistry; and Tapio Nikkilä for scanning electron microscopy of the mites. We are grateful to Torsten Mörner for his support to conduct this study as part of the wildlife surveillance program.

\section{References}

I. Yeruham I, Rosen S, Hadani A: Chorioptic mange (Acarina: Psoroptidae) in domestic and wild ruminants in Israel. Exp Appl Acarol 1999, 23:861-869.

2. Zahler M, Hendrikx WML, Essig A, Rinder H, Gothe R: Taxonomic reconsideration of the genus Chorioptes Gervasis and van Beneden, 1859 (Acari: Psoroptidae). Exp Appl Acarol 200I, 25:517-523.

3. Wall R, Shearer D: Psoroptidae. In Veterinary Ectoparasites: Biology, Pathology and Control 2nd edition. Edited by: Wall R, Shearer D. Oxford: Blackwell Science; 200I:34-39.

4. Sweatman GK: Life history, non-specificity, and revision of the genus Chorioptes, a parasitic mite of herbivores. Can J Zool 1957, 35:641-689.

5. Essig A, Rinder H, Gothe R, Zahler M: Genetic differentiation of mites of the genus Chorioptes (Acari: Psoroptidae). Exp Appl Acarol 1992, 23:309-318.

6. Bates PG: Inter- and intra-specific variation within the genus Psoroptes (Acari: Psoroptidae). 1999, 83:201-217.

7. Sweatman GK: Redescription of Chorioptes texanus, a parasitic mite from the ears of reindeer in the Canadian arctic. Can J Zool 1958, 36:525-528.

8. Hirst S: On a new mite of the genus Chorioptes parasitic on goats in the United States. Ann Mag Nat Hist 1924, $13: 538$.

9. Hirst S: Description of new mites, including four new species of "red spider". Proc Zool Soc Lond 1926:825-84I.

10. Dorny P, Van Wyngaarden T, Vercruysse J, Symoens C, Jalila A: Survey on the importance of mange in the aetiology of skin lesions in goats in peninsular Malaysia. Trop Anim Health Prod 1994, 26:8|-86.

1I. Kadulski S: Ectoparasites of Cervidae in north-east Poland. Acta Parasitol 1996, 41:204-210.

12. Kadulski S: Further studies on parasitic arthropods of the elk, Alces alces in Poland. Wiad Parazytol 1996, 42:349-355.

13. Kadulski S: Ectoparasites of sika deer in Poland. Acta Parasitol 2000, 45: 163.

14. Naturvårdsverket [http://www.naturvardsverket.se/Arbete-mednaturvard//akt-och-viltvard//akten-i-Sverige/Antal-falld-djur/]

15. Mörner T: Älg. In Liv och Död Bland Vilda Djur Edited by: Mörner T. Stockholm: Sellin \& Partner Förlag AB; 1992:21-29.

16. Bornstein S, Gavier-Widén DM, Rinder M, Bröjer C, Uhlhorn H, Ågren E: Chorioptic ear mange in moose (Alces alces). A pilot prevalence study in the Swedish wild moose population. 6th meeting of the European Wildlife Disease Association, 9th-12th September, 2004, Uppsala, Sweden .

17. Matson GM: Workbook of cementum analysis Montana: Matson's; I98I.

18. Fain $A$ : Nouveaux taxa dans les Psoroptinae. Hypothèse sur l'origine de ce groupe (Acarina, Sarcoptiformes, Psoroptidae). Acta Zool Pathol Antverpiensa 1975, 61:47-56.

19. Fain A, Leclerc M: Sur un cas de gale chez le panda géant produit par une nouvelle espèce du genre Chorioptes (Acarina: Psoroptidae). Acarologia 1975, 17:177-182.

20. Zahler M, Gothe R, Rinder H: Genetic evidence against a morphologically suggestive conspecificity of Dermacentor reticulatus and D. marginatus (Acari: Ixodidae). Int J Parasitol 1995, 25:|4|3-1419.

21. Thompson JD, Higgins DG, Gibson TJ: CLUSTAL W: improving the sensitivity of progressive multiple sequence alignment through sequence weighting, position-specific gap penalties and weight matrix choice. Nucleic Acids Res 1994, 22:4673-4680.

22. Morrison DA: Multiple sequence alignment for phylogenetic purposes. Aust Syst Bot 2006, 19:479-539.

23. Zucker M: Mfold web server for nucleic acid folding and hybridization prediction. Nucleic Acids Res 2003, 31:3406-34I5.

24. Swofford DL: PAUP*: Phylogenetic Analysis Using Parsimony (*and Other Methods) Sunderland MA: Sinauer Associates; 2002.

25. Nixon KC: The parsimony ratchet, a new method for rapid parsimony analysis. Cladistics 1999, 15:407-414.

26. Morrison DA: How to find the maximum-likelihood tree in a phylogenetic analysis of up to 150 nucleotide sequences. Syst Biol in press.

27. Posada D, Crandall KA: Modeltest: testing the model of DNA substitution. Bioinformatics 1998, 14:817-818.

28. Sullivan J, Abdo Z, Joyce P, Swofford DL: Evaluating the performance of a successive-approximations approach to parameter optimization in maximum-likelihood phylogeny estimation. Mol Biol Evol 2005, 22: 1386-1392.

29. Lendrum AC: The staining of eosinophil polymorphs and enterochromaffin cells in histological sections. J Pathol Bacteriol 1944, 56:44I.

30. Lavoipierre MMJ: A preliminary description of a new species of Chorioptes from an African antelope. Ann Trop Med Parasitol 1958, 52:384.

31. Rosen S, Yeruham I, Hadani A: Chorioptes texanus (Hirst, 1924), Psoroptidae on cattle in Israel. Acarologia 1989, 30:373-376.

32. Lavoipierre MMJ: A description of the male and female of Chorioptes crewei Lavoipierre 1958 (Acarina: Psoroptidae), together with some remarks on the family Psoroptidae and a key to the genera contained in the family. Acarologia 1959, I:354-364.

33. Wang DQ, Sun YM, Wang LL, Chen YC: Study on the external morphology of different stages of Chorioptes panda Fain et Leclerc (Acariformes: Psoroptidae). Wuyi Sci J 1985, 5:99-104.

34. Anonymous: Manual of Veterinary Parasitological Laboratory Techniques. Reference Book 4I8,. Ministry of Agriculture, Fisheries and Food London: Her Majesty's Stationary Office; I97I.

35. Sargison ND, Scott PR, Wilson DJ, Bates PG: Chorioptic mange in British Suffolk rams. Vet Rec 2000, July 29:135-136.

36. Shibata A, Yachimori S, Morita T, Kanda E, Ike K, Imai S: Chorioptic mange in a wild Japanese serow. J Wild Dis 2003, 39:437-440.

37. Scott DW: Parasitic diseases. In Large Animal Dermatology Edited by: Pedersen D. Philadelphia: W.B. Saunders; 1988:39-49. 222-225

38. Gross TL, Ihrke PJ, Walder EJ, Affolter VK: Superficial spreading pyoderma and Perivascular diseases of the dermis. In Skin Diseases of the Dog and Cat. Clinical and Histopathological Diagnosis Oxford: Blackwell Science Ltd; 2005:6-9. 200-2।I, 216-2।9

39. Abbas AK: Diseases of immunity. In Robbins and Cotran Pathologic Basis of Disease 7th edition. Edited by: Kumar V, Abbas AK, Fausto N. Philadelphia: Elsevier Saunders; 2004:205-2I8.

40. Scott DW, Miller WH: Parasitic diseases. In Equine Dermatology Edited by: Kersey R. St Louise: Elsevier Science; 2003:33I-334.

41. Carter GR, Chengappa MM, Roberts AW: Staphylococcus. In Essentials of Veterinary Microbiology Edited by: Cann C. Baltimore: Williams \& Wilkins; 1995:1 15-120.

Publish with Biomed Central and every scientist can read your work free of charge

"BioMed Central will be the most significant development for disseminating the results of biomedical research in our lifetime. "

Sir Paul Nurse, Cancer Research UK

Your research papers will be:

- available free of charge to the entire biomedical community

- peer reviewed and published immediately upon acceptance

- cited in PubMed and archived on PubMed Central

- yours - you keep the copyright
BioMedcentral 